\title{
Problematizing resilience: Implications for planning theory and practice
}

\author{
Barbara Pizzo \\ Department of Planning, Design and Technology, Sapienza Università di Roma, Italy
}

\section{A R T I C L E I N F O}

\section{Article history:}

Received 11 November 2013

Received in revised form 25 November 2014

Accepted 27 November 2014

\section{Keywords:}

Urban resilience

Resilience and planning

Planning theory and practice

\begin{abstract}
A B S T R A C T
This paper problematizes the introduction of the concept of resilience into the planning domain from three main starting points: 1 . The nature of the events which are said to require resilience; 2 . The different nuances in meaning that resilience assumes according to those different events, and 3 . The theoretical and operational problems the concept entails. The paper sustains that: 1 . The quest for a resilient behavior or a resilient answer, and the claim to improve urban and territorial resilience do not find the same justification in every kind of event; 2 . Multiple sub meanings are embedded within one interpretation of resilience that leave the concept open to rather large margins of ambiguity, which emerge considering its operationalization; 3 . The concept seems to fit and to be appropriate within different paradigms, planning traditions and policy frameworks. Its alleged 'neutrality' is one of the main reasons of its pervasiveness, but also of its ambiguity, showing latent controversial implications, which are progressively emerging in critical planning theory.
\end{abstract}

(c) 2014 Elsevier Ltd. All rights reserved.

\section{Introduction}

Etymologically, resilience derives from Latin resilire, and specifically from the prefix 're-', which suggests going 'backwards' or 'counter', added to the verb 'salire', which means 'to jump' and shares its root with the Greek $\alpha \lambda \lambda \mathrm{o} \mu \alpha \mathrm{l}$ - a verb whose meaning is 'to spring back' and 'to rebound' but also, significantly enough, 'to withdraw'.

The word has a very long history, which can be traced back at least to the 1 st Century B.C. But unlike what has been argued in an interesting excursus (Alexander, 2013), the first occurrence of the word can be found in the poem On the Nature of Things by Lucretius, where it conveys the specific meaning of being forced back by a resisting surface, as in Book 4, 323ff, with reference to the action on Nature, similar to the 'bouncing back' of an image from a mirror: Nature so compels/all things to be borne backward and spring off (resilire)/at equal angles from all other things. Although the term has been used with different meanings and within different semantic contexts since it appeared for the first time, recurring in essays or poetry about Nature (Lucretius, Pliny the Elder, Ovid), as well as in political dissertations (Cicero), and in technical essays (Vitruvius), it refers to the notion of rebounding in its most common use. This capacity is described in the field of Mechanics as the power or ability of a body or a material to return to its original state after being altered, due to the potential energy that has been stored through modification from a previous state.

E-mail address: barbara.pizzo@uniroma1.it
The main characteristic of this physical quality is that of 'bouncing back', and of using the same solicitation which caused the alteration (as for elastic power) to return to previous conditions.

An important shift of meaning results in transferring the concept into systems theory, as occurred in modern times primarily through the work of Crawford Stanley Holling. Holling (1973, p. 14) defined resilience as "a measure of the persistence of systems and of their ability to absorb change and disturbance and still maintain the same relationships between populations or state variables" in various ecological systems-related examples. Since then, the term started to run through almost all the disciplines and languages concerning individuals and institutions, as well as cities and territories. Its multidisciplinarity and its adaptability within dynamic systems and complexity theories make the concept attractive (Garschagen, 2011). So resilience has been frequently redefined and extended by heuristic, metaphorical, or normative dimensions (e.g., Holling, 2001; Ott \& Döring, 2004; Pickett et al., 2004).

Zolli and Healey (2012, p. 16) sustain that resilience touches and affects a variety of sectors (from business planning to social development, from urban planning to national energy security), and propose it as "a powerful lens through which we can view major issues afresh" in a recent and widely - debated publication.

Resilience Alliance (http://www.resalliance.org) states that resilience has three defining characteristics: (1) the amount of change a system can undergo and still retain the same controls on function and structure, (2) the degree to which the system is capable of self-organization, and (3) the ability to build and increase the capacity for learning and adaptation 
(http://www.resalliance.org/index.php/resilience; see also: Resilience Alliance 2007a, 2007b). However, it has been noted that the first one is the most widely-employed (Carpenter \& Brock, 2008). Indeed, while particularizing an already established definition, which sees resilience as the capacity of a system to respond to change or disturbance without changing its basic state (Walker \& Salt, 2006), Zolli and Healey (2012, p. 126) define resilience as the ability of people, communities, and systems to maintain their "core purpose and integrity in the face of dramatically changed circumstances", with the key factors being agility, adaptation, and the ability to face change in flexible ways (Chapin, Folke, \& Kofinas, 2009).

This interpretation cannot but recall a broader claim to flexibility, "the watchword with respect to labour markets" (Harvey, 2005; Sennet, 1998), a cornerstone of the current neoliberal agenda.

A Thomas Bernhard novel came to my mind, The loser (whose German and Italian titles - respectively: Der Untergeher, and Il soccombente-, sound highly appropriate for this reflection) when starting to consider resilience in its translation into social sciences and specifically into the planning field. The novel speaks of a person who was not at all resilient, who just suffered from the casualties and adverse situations life reserved him, a victim. But a victim of what: of his own weakness, of external events, or both? Do causes (still) count?

Wertheimer had to commit suicide, I told myself, he had no future left. He'd used himself up, had run out of existence coupons. (...)

Wertheimer was always and only the loser. I've always been the weak one, absolutely the weak link, so Wertheimer. (...)

The two of us, Wertheimer and myself, had had to give up to make room for Glenn. At the time I didn't find this thought as absurd as it now seems to me, I thought. But Glenn was already a genius when he came to Europe and took Horowitzs course, we were already failures then, I thought. (...)

\section{[T. Bernhard, The Loser [Der Untergeher]]}

The concept of resilience entered into the planning domain with different orientations. Although most of the attention is still focused on environmental issues, and a large part of explorations are dedicated to the reduction or mitigation of environmental risks such as earthquakes, floods, hurricanes, and global warming, we are witnessing a rather impressive increase of the fields where the concept is used.

This leads to a considerable semantic extension, with problems of clarity, certainty, and understanding what sense and meaning the concept actually assumes in policy discourses, as well as in its translation into practice.

As often occurs for mainstream concepts, and as many scholars promptly noted (Davoudi et al., 2012), resilience risks being reduced to a buzzword: if we want to keep resilience as a useful notion, we need to correctly and specifically narrow the concept and its use. However, in my view this is not the primary problem. Instead, I consider its political meaning to be of the utmost importance. While it is often presented as a politically neutral approach, resilience demonstrates an inherently conservative nature.

A comparison with sustainability, provided by Redman (2014), helps to clarify this. As Redman perceptively observed when considering 'sustainability-transformation'/'resilience-adaptation': "The current political arena favors adaptation because it works to maintain the established order and address near-term problems. Citizens and their elected officials are more comfortable with adaptation because it appears less radical than transformation, which involves uncertain outcomes and the associated costs of system restructuring. Consequently, resilience approaches are popular in today's political arena".
However, fundamental limits to resilience thinking emerge insofar as the transformation of a system (in its current ecological, social, or economic characters) may be required or desirable; and also insofar as there are systems (such as criminal organizations) that prove to be highly resilient, but most definitely undesirable.

Furthermore, resilience tends to consider very different events (a flood, a war, a social upheaval) as essentially equal, without distinguishing what is unexpected from what is contentious or unwanted. Since resilience thinking envisages all possible events in abstract terms, this offers proof of its analytical/descriptive origin, unlike sustainability, which "rigorously integrates normative values and anticipatory thinking into a scientific framework (Clark \& Dickson, 2003; Swart, Raskin, \& Robinson, 2004)" (Redman, 2014).

The shift from an analytical perspective to a normative one is not straightforward. On the contrary, the subtleties and ambiguities that resilience brings together emerge from this shifting between different levels.

For example, ascertainment of the resilient behavior of a community after an unexpected event does not necessarily mean that all communities must be resilient, nor that they must be resilient whatever event they experience, nor that they must be resilient in the same way as the one observed, and even less obvious is the definition of how resilience should be pursued. Clearly, it is not just an extension of the meaning, but a move from a phenomenological outlook to an ethical and political perspective.

Above all, it is not yet clear if resilience should become a paradigm - and to what extent it could influence planning as a discipline with a normative approach.

In this paper I problematize the introduction of the concept of resilience into the planning domain from three main starting points: 1 . The different nature of the events that would require resilience of urban and territorial structures, and/or a more resilient planning; 2 . The different nuances that the concept assumes when referring to various events, and more specifically when moving from an analytical to a normative perspective; 3 . The theoretical and operational problems the concept entails - that also includes the different meanings and implications arising from considering the aforementioned differences. The paper argues that: 1 . The quest for resilient behavior or response, and the claim to improve urban and territorial resilience do not find the same justification in every kind of event or, in other words, not each kind of event justifies the claim to resilience; 2 . Multiple sub meanings are embedded within one interpretation of resilience which leave the concept open to rather large margins of ambiguity that emerge considering its operationalization; 3 . The concept seems to fit and to be appropriate within different paradigms, planning traditions and policy frameworks. For this reason, despite a conservative approach, it ranks as a 'neutral' interpretive and operational concept and (because of that) it tends to hide the political nature and political meaning of choice, contributing to the de-politicization of the issues at stake and of the related decisions.

Brief references to current planning practices addressed to environmental (seismic) risk prevention and mitigation in Italy are provided to reinforce the argument, showing how recourse to the concept of resilience can be interpreted within and through different theoretical frameworks, also indicating further directions of research.

\section{About the different nature of events that would require the resilience of urban and territorial structures. [Do causes count?]}

Resilience became an object of planning research starting with a consideration of the different interpretation of the concept rooted 
in various disciplinary traditions, and namely engineering or ecological and social sciences. If, as Friedmann (2008) states, we are to assume that 'translation' is one of planning theory's tasks, the prime reason for such research resides in the need to find which root fits better with our discipline. Since cities can be interpreted as complex adaptive systems whose organization and behavior are comparable to ecosystems, most scholars agree that the meaning urban planning adopts is the one related to the ecological/ social side of the concept. But this need to be developed further.

Holling's definition is applied to urban and territorial systems as regards their ability to absorb change and disturbance while still maintaining the same state of equilibrium. It is used by many other authors and, within literature, is almost interchangeably used with the terms ecological resilience and ecosystem resilience (Brand \& Jax, 2007 , p. 24). The concept is now adopted by various scientific subjects as an approach to analyzing ecological, as well as social-ecological systems (Anderies, Walker, \& Kinzig, 2006; Folke, 2006). A specific focus is on the capacity to adapt to environmental hazards and disasters. In this respect, a definition of resilience by Klein, Nicholls, and Thomalla (2003, p. 43) shows promising developments for disaster risk reduction. They argued that "maintaining and enhancing adaptive capacity should be the overall goal of resilience"; this interpretation signals a fundamental shift from the analytical to the normative level.

While Pickett et al. (2004), in their work on the ways to improve integration between ecology, urban planning and design, and with reference to the metaphor of cities of resilience, highlighted how an equilibrium-related definition of resilience is not suitable for cities and urban planning. They defined resilience as "the ability of a system to adjust in the face of changing conditions" and considered this meaning more appropriate in the field of urban studies since cities, and the urban environment in general, are continuously changing.

Many other definitions have been introduced in literature under the umbrella of ecological and social sciences. Under the social science umbrella, Adger (2000, p. 347) defined resilience as "the ability of groups or communities to cope with external stresses and disturbances as a result of social, political, and environmental change". According to Hutter, Kuhlicke, Glade, and Felgentreff (2011) community resilience does not exactly amount to the sum of people's inner resistance and adaptability to external factors. Lack of resilience at one level (from the individual to the world) can undermine resilience at other levels.

Planning uses both meanings of resilience, the one connected to natural and ecological systems and the one related to the social and civic components of society, since both represent the main focus of planning. However, according to Alexander (2013), a problem may lie in attempts to make resilience a full scale paradigm. In fact: "as other authors have noted, as a concept, resilience involves some potentially serious conflicts or contradictions, for example between stability and dynamism, or between dynamic equilibrium (homeostasis) and evolution. Moreover, although the concept of resilience works quite well within the confines of general systems theory, in situations in which a systems formulation inhibits rather than fosters explanation, a different interpretation of the term is warranted. This may be the case for disaster risk reduction, which involves transformation rather than preservation of the 'state of the system"' (Alexander, 2013, p. 2707).

Furthermore, in explaining the differences between the engineering and the ecological interpretation of resilience according to Holling's seminal work and its subsequent developments (Holling, 1973, 1996), it has been noted that the difference mainly consists in the kind (or degree) of equilibrium each disciplinary tradition considers: "a pre existing one to which a resilient system bounces back (engineering) or a new one to which it bounces forth (ecological)" (Davoudi et al., 2012, p. 301). It has been argued that the return to a previous stable equilibrium is not usually the case in real ecological systems (Pickett, Parker, \& Fiedler, 1992; Pickett et al., 2004; Pulliam \& Johnson, 2001), and therefore a more dynamic and evolutionary approach has been adopted (Davoudi et al., 2012, 2004). Thus, "ecological resilience rejects the existence of a single, stable equilibrium, and instead acknowledges the existence of multiple equilibria, and the possibility of systems to flip into alternative stability domains" (Davoudi et al., 2012, pp. 300-301).

However, the focus is on what kind of equilibrium they refer to, regardless of the causes that may alter it, or the reasons that would preserve it. In fact, it is said that alterations can come from "either a natural disaster, such as flooding or earthquakes, or a social upheaval, such as banking crises, wars or revolutions" (Davoudi et al., 2012, p. 301). Any cause looks the same, and resilience always seems to be the right answer, so that the idea of a 'panarchy' (Gunderson \& Holling, 2002) was introduced.

I can see some critical points in this wide and unbounded recourse to the concept of resilience. These problems emerge especially when resilience ceases to be an analytical category and starts to be used with a normative orientation. Unexpected, unforeseeable events are quite different from unwanted events, suggesting that different answers and reactions are required. A social upheaval is not a hurricane: they generate and require different reactions. Moreover, the quest for resilience means different things if we apply it within the context of a specific, time-framed crisis (post-earthquake, or flood emergency), or in an specific time context, and its extension to all possible crisis situations is not so 'obvious' as often presented (in this sense, it would be interesting to take a closer look at its relation with the Greek concept of 'crisis' ( $\kappa \rho i \sigma ı)$ ) whose first meaning is that of a radical turn or shift which implies a decision).

Resilience is often interpreted as the ability to adapt to more challenging conditions, as an outcome of extra-ordinary events. It would not have the same meaning and implications if this condition were looked on as a 'new', un-limited state, which we have to face (a 'crisis' cannot last forever, it stands out as fixed and even specific, its meaning expresses change as a turn after - or because of - a relatively precise point or discontinuity). In other words, we have a quite different theoretical - and political - scenario if resilience is adopted in its more general terms and with a normative approach, as a way to manage an unbalanced world, whatever the reason for the changes, including unwanted and highly contested changes. In my view, notwithstanding some interesting studies that started to critically point out this problem, unbounded recourse to resilience and its translation into a normative category represents an unresolved and controversial issue, which is worth looking at in greater depth.

\section{About the different nuances the concept assumes when referred to the various possible events}

In spite of major efforts to demonstrate the complexities and versatility of resilience, and the multidimensional challenge it represents, few studies to date have tried to cope with this multidimensionality by proposing tools or indicators that assess urban resilience in its different dimensions - physical, natural, social, economic, and institutional (e.g. Ainuddin \& Routray, 2012; Cutter et al., 2010; Prashar et al., 2012). Moreover, most of that small number of studies deal predominantly with natural hazards.

A large part of resilience-oriented studies focus on the reduction or mitigation of environmental risks, such as seismic risk, flooding, global warming, representing a major field of mutual research for natural sciences and urban planning (see, e.g.: UNISDR (2012) and Vale and Campanella (2005)). On the other hand, focusing on just one field will allow problems to emerge more clearly. 
I will dwell on two aspects herein. 1. The concept that resilience may be used in different ways and with different orientations emerges even within literature and experiences circumscribed to environmental risks. 2 . It is possible to understand what the imperative of resilience actually means, especially as regards planning and policy by highlighting these differences. A decisive step toward comprehension is provided by critically investigating the reason for and meaning of the shift from the sustainability paradigm to resilience.

Earthquakes, floods and global warming require different spatial- and time frames for policies and action: while the first two cases are often dominated by an emergency approach addressed to specific areas, the last one represents a long-term, planetary challenge. The two frames are not mutually exclusive, but imply different definitions of resilience. Indeed, it has been noted that "resilience-building literature is dominated by post-disaster emergency planning, where the focus is on sudden, large and turbulent events, at the expense of gradual, small and cumulative changes" (Davoudi et al., 2012, p. 302). In order to allow the different nuances the concept of resilience may assume to emerge, it is more useful to circumscribe the inquiry to one field, in the case in point to that of seismic risk. Experiences provide clear examples where emergency action is set against long-term risk prevention and risk mitigation strategies, showing conflicting views and alternative policy frames that the claim to resilience is unable to resolve.

Italy has always been subject to recurrent catastrophic events (such as earthquakes, landslides, floods, etc.). Italy has an especially serious seismic history like a few other European countries, such as Turkey and Greece. Despite this, a major gap emerges if we are to consider the high level of seismic risk and high recurrence of seismic disasters, and the lack of public policies and actions focusing on prevention, which is paradoxical.

This gap has long since been recognized, at least in scientific and academic debate, and increasingly at civil society level. Nevertheless it has not resulted either in the affirmation of policies and actions focusing on prevention, nor in standard policies dedicated to territorial maintenance, which would represent a major improvement of public action as regards efficacy and cost-efficiency (Pizzo, Di Salvo, Giuffré, \& Pellegrino, 2013; Pizzo \& Fabietti, 2013).

Now that the concept of resilience features increasingly in the debate about how to manage 'natural disasters', without producing effective changes in terms of results, it could be of some interest to critically deconstruct and historically reconstruct said debate.

First of all, it is quite evident that between alternative postdisaster emergency action policies and gradual and cumulative improvements, the choice has often been the former.

Italy is negatively known for its recurrent use of 'emergency policies' despite a vast number of approaches, methods and tools related to planning, focusing on mid-long term prevention policies resulting from actual experiences, mainly at a regional level. They can be interpreted as a sign of a minor ability to pursue a long-term public policy, but also of the dominance of short-term views.

Emergency became the causal force and justification for public action to be fast implemented, significantly reducing the process of deliberation (Pizzo \& Fabietti, 2013; Pizzo et al., 2013). An abstract claim to resilience does not solve this problem, on the contrary, it could sharpen it.

Resilience is interpreted as a way to help individuals, communities and systems to carry on and to linger, possibly also to revive, even if amidst unforeseeable disruptions. This definition theoretically admits both the short-term emergency and mid-long term risk mitigation approaches. In other words, an increase in resilience could be the answer for managing isolated, 'extra-ordinary' and highly disruptive events, and/or a way to prevent their potential damage in the mid-long term, thus demonstrating how the concept can be used within different frameworks and for different objectives and purposes.

Furthermore, the problem of what resilience should be pursued - and how - remains even within one individual field of action such as seismic risk prevention, since basically, resilience proves to be the uncertain product of many different actions. For example, the ability of a historical town (a common occurrence in Italy) to respond to a seismic event and to re-organize itself for recovery (this ability being interpretable as its resilience) can be achieved through different choices: keeping the main and strategic functions within old buildings by improving or re-designing facilities and infrastructures, or relocating them outside the historical center, often in new, anti-seismic buildings. The two alternative scenarios have different social, economic, environmental and spatial implications, and are commonly intertwined with other goals and actions to implement them. Their definition, also in terms of pros and cons, is the field of action of planning. The choice between these different modes of action is a political one. A general and abstract call to resilience says nothing about the actual changes that must be made in order to obtain the desired results. Moreover, despite various possible actions, resilience might prove to be not significantly increased. In this sense, resilience can be considered as a sort of 'by-product' of policies and actions focusing on multiple objectives. This represents a fundamental problem, to be tackled before including resilience within planning tasks. Since a by-product cannot be directly obtained (Pizzo, 2005, 2007), what planning should aim to do is to pursue those different objectives, debating them in their own specific political arenas, and keeping resilience as a more general goal to head toward. This implies being able to manage uncertain outcomes, as well as failures, but not necessarily to 'accept' them. Even so, contemporary planning is used to thinking and acting in uncertain conditions, aware that the result of its action may be different from what is expected.

The shift from sustainability to resilience is another step I would like to briefly discuss herein.

For decades sustainability has been the keyword and a fundamental point of reference for people concerned with environmental problems, especially in their relationship with economic and social ones. Its ubiquity and (the risk of) its ineffectiveness have been criticized. Resilience is presented both as its twin and as its opposite, as a sort of 'current translation' or as a substitute of sustainability, depending on when and where the two concepts are mentioned. Resilience is often presented as the 'new' upgraded version of sustainability, able to challenge the sustainability paradigm 'from within', but it is also presented as a different concept, set within a different paradigm. While the concept of sustainability brings with it the idea that we can achieve a more balanced and fair world with the right action, resilience takes the imbalance of our world, and our imperfect knowledge of it as a given, considering flexibility to be the only practical answer to an uncertain future. This is said to have been largely ignored within the paradigm of sustainability. The ability to anticipate and foresee future scenarios is placed against the ability to (strategically) react, which would also help to adapt to unexpected changes (more and before being able to reach the better and fairer world we aspire to). This is why it does not represent a minor change of perspective (as it could sometimes seem, when we find the two concepts of sustainability and resilience used as quasi-synonyms, or the second one as the 'natural' development of the first one), but rather a major one.

Many scholars also try to combine the two different approaches. Interestingly, Redman admits that transformative actions could be conceived as part of a resilience approach (Folke et al., 2010; Olsson et al., 2006) when future states are left flexible, and the main goal is to improve the robustness of the system; at the same time he notes the problems and even the setbacks of combining resilience and sustainability, pointing out the differences and 
potential contradictions among the fundamental assumptions of each approach, also explaining how actions focusing on improving sustainability should result in reducing resilience (Redman, 2014). Through renaming socio-ecological resilience as 'evolutionary resilience', Davoudi, Brooks, and Mehmood (2013) tries to overcome this discrepancy too, but the introduction of the new concept does not resolve the prevailing problems of operationalization and theorizing.

Moreover, the main thing I understand from Redman's argument is the different derivation and political meaning of the two concepts, and the different way in which the agent-system relationships are defined and shaped.

As regards political meaning, while sustainability proves to be related to a transformation mindset, with scientists aiming to create a new order in a 'open ended' process that also allows more radical transformations of the system, resilience is definitively related to an adaptation mindset, where the aim is to maintain the previous order: "adaptive strategies are relatively conservative: under the pressure of changing conditions, these strategies serve to maintain or return the system to the previous order or one similar to it" (Davoudi et al., 2013).

As far as agent-systems configurations are concerned, another significant difference emerges. In fact, since sustainability science has a normative orientation, agents are expected to intervene and to change the system in the desired direction in the sustainability approach. While, given its analytical/descriptive origin, resilience thinking analytically assumes that agents are part of the system, and the result of their action is not (cannot be) predetermined, "theoretically, a resilience approach is not intended to choose among outcomes, but focus on system dynamics that might be favored over others" (Redman, 2014).

\section{About the different meaning and implication of the different natures and nuances of resilience}

Like many other concepts derived from natural sciences, resilience is used as "a politically neutral, commonsense policy objective, underpinned by a pragmatic philosophy" (Raco \& Street, 2011, p. 1066). First and foremost, we already noted that resilience could be seen as the ability to adapt to unexpected catastrophic circumstances or critical events, even to 'unwanted' change. In my view, that 'even' contains a universe of meanings and implications that make the concept not generally useful, while stressing planning (if not contradicting it) in its utmost meaning and in its more widely recognized tasks. In fact, planning can be defined as a way to drive socio-economic change through forms of control over space (Mazza, 2002, 1995, 2013), to foresee future scenarios, and to try to pursue the best among the options to achieve increasingly better socio-spatial configurations. This also implies thinking about ways and strategies to avoid unwanted, undesirable outcomes.

The move toward resilience is often justified through the argument of an increasing level of uncertainty in an increasing complex world (Berkes \& Folke, 1998). Resilience is presented as a fundamental improvement in managing uncertainty, and specifically through the shift from 'risk mitigation' to 'risk adaptation' mindset.

The origin of this interpretation can be traced back to Aaron Wildavsky 'Searching for Safety' (Wildavsky, 1998), where the precautionary principle and anticipatory risk regulation mindset are scrutinized and overcome. While the risk mitigation mindset and its precautionary principle are based on 'trial without error', the risk adaptation mindset is based on 'trial and error' logic: this constitutes the nature of resilience. Wildavsky argued that "the direct implication of trial without error is obvious: if you can do nothing without knowing first how it will turn out, you cannot do anything at all". So, his thought is used to demonstrate that we have to learn to act even without knowing, accepting that the result may not be what we wanted or hoped for. It has been argued that this perspective challenges planning, its approaches and tools (such as trend analyses). Thus a basic question emerges: "Does this mean that in a world defined by constant change and uncertainty 'planning is condemned to solve yesterday's problems' (Taylor, 2005, p. 157)?" (Davoudi et al., 2012, p. 303).

Indeed, planning theory and practice have long since dealt with uncertainty. There is no need to recall that uncertainty is one of the main reasons behind the crisis of the so-called rational-comprehensive paradigm, and that some planning approaches, like incremental planning, and strategic planning, have been developed over time in order to provide a more satisfying answer to that claim. Therefore, the move toward resilience cannot mean the "start' of managing uncertainties which is already part of planning. What does it means to demand more 'resilient' planning, given the availability of planning traditions and 'styles' that are close to resilience thinking? What emerges from many definitions of resilience is a feeling of ineluctability and acquiescence: our world is something that we cannot change, we cannot even say anything about the change and about the future, we just have to learn to live with it as it is in the present conditions, or as it will be, learning to follow the change, and to re-organize ourselves and our environments in the most 'advantageous' way. How? For whom? These questions remain largely unanswered in current literature on resilience and resilience planning, with just a few exceptions.

What happens to those who are not able (or less able than others) to adapt or to react? This leads to another critical point of the present issue, namely the risks of assuming a kind of naturalistic determinism (or deterministic naturalism), separating the course of events from free will - and also from the historical perspective. This tendency is not a new one. On the contrary, it almost regularly occurs over time. Some of the problems related to a deterministic, mechanical view of the world have been already pointed out (Davoudi et al., 2012), and the extreme consequences of transferring such a paradigm into society have already demonstrated their sad and dreadful consequences. Resilience is said to be able to achieve better conditions through some kind of evolutionary, organic solution, even given a continuously changing world and even if these conditions cannot be predicted. This implicitly means that the new conditions are just 'eventual', in the sense that they depend on a chain of events that evolves - partially or fully - out of our control. As already noted, this character of resilience poses fundamental epistemological and ethical problems to planning: firstly, the normative translation of resilience from the analytical plan, where it originated, is not straightforward; secondly, resilience proves to be more comparable to a 'by-product', and this means that it cannot be a direct aim of planning; thirdly, the ability to manage uncertain outcomes and also failures, does not necessarily imply acquiescence.

Moreover, from a planning perspective the ecological definition of resilience is said to be preferable (Davoudi et al., 2012), presumably this depends on some similarities in its way of schematizing processes. For example, the cycle describing the changes of an ecological system, from growth or exploitation and conservation, to release or creative destruction, and subsequently to reorganization (Gunderson \& Holling, 2002), reminds us of the phases of institutionalization, de-institutionalization and re-institutionalization proposed in 1966 by Berger and Luckmann and those of territorialization, de-territorialization and re-territorialization (Deleuze \& Guattari, 1972), in this case representing an established interpretation of spatial structuring processes. However, this supposed albeit stimulating parallel between natural and social science interpretations risks generating significant misunderstandings, since institutional and territorial processes are marked out by human will and 
human choice and behavior, that should be historically contextualized, and not by 'natural laws'.

If we consider an ecological framework we have to accept the consequences that that paradigm generates: what counts is the whole ecosystem, individuals and communities are subjects to its needs and to its laws. Having considered all of this, in my view the translation of these principles into the domain of social sciences poses two main problems: 1 . It could lead to forms of neosocial-Darwinism; 2. It goes hand-in-hand with a new move toward 'scientific-technical' responses, which has already been explored in depth with regard to its role in de-politicizing Nature, as well as environmental-societal relationships (Swyngedouw, 2007; Swyngedouw, 2011).

A last point in this argument considers resilience and its implications in the light of a critical interpretation of neoliberalization. Almost paradoxically while resilience shows a conservative disposition, especially if compared with sustainability, it is said to contribute to fixing a radical agenda (Shaw, in Davoudi et al., 2012), thus demonstrating how the political meaning of resilience is quite contentious. Moreover, resilience can be seen as a stimulus for increasing improvisation and imagination, as well as the will and as a call - to accept the existing conditions and power relations. It is interpreted "as a buffer capacity for preserving what we have and recovering to where we were (Folke et al., 2010). The emphasis is on the return to 'normal' without questioning what normality entails" (Pendall, Foster, \& Cowell, 2010 cited in Davoudi et al., 2012, 302). Again, the concept shows its inherent ambiguities. Whether both the more conservative and the more innovative and progressive interpretations of the term are recognized, studies are demonstrating that it is mostly exploited in the first version (Raco \& Street, 2011).

In fact, the increasing importance of resilience suggestively reached its peak in conjunction with the credit crush of 2008-2009: this was when it started to be considered as the new keyword, and when extensive, trans-disciplinary discourses on resilience started to be constructed and widely circulated. This relationship is worth examining, and so it is a more general understanding of the meaning and sense of the recourse to such a concept from a political viewpoint.

Significantly, as a result of the economic recession, the question of environmental balance (from a local to a global scale) started to be seen together with, and through, the perspective of the economic crisis, which affects most of the 'global North' countries highlighting the extent of the imbalance in our world. It becomes necessary to imagine different socio-spatial configurations (more resilient ones) or, in other words, to think of different urban and territorial models. In fact, "the rise of resilience can be viewed as part of the lexicon of the 'new austerity', where economic recession and public expenditure crisis, the depletion of natural resources and the challenge of mitigating and adapting to climate change constitute a crisis of an altogether different order (WenbanSmith, 2011, p. 431)" (Shaw, in Davoudi et al., 2012), opening new perspectives to manage new complexities, and trying to face a growing and spreading sense of insecurity. Significantly, it is said that "broadly speaking, the contemporary sustainability movement has been (rightfully) preoccupied with risk mitigation for some time. Yet as irrevocable global changes of all sorts edge closer, a shift toward adaption - and with it an increasing focus on resilience - is underway. And not just in sustainability, but in many areas of significant future risk - from global economy to public health, poverty alleviation to corporate strategy" (Zolli \& Healey, 2012, pp. 22-23): - instead of reaching a balance, which was the aim of sustainability, resilience takes the imbalance of the world as a given, and looks for ways to manage it - which implicitly means that we have 'to somehow accept' this imbalance, and its causes.
Moreover, adaptive strategies and so resilience are very often specific and local, they are conceived and implemented to act on the periphery of the system, not to change the system but to adjust it in order to conserve or replenish it. Redman highlighted this point, saying that "adaptive strategies are relatively conservative: under the pressure of changing conditions, these strategies serve to maintain or return the system to the previous order or one similar to it" (Redman, 2014).

Resilience is presented as the answer to both the environmental imbalance and the economic crisis we are facing. What does it mean to call for resilience when facing an economic crisis? Does it mean that we are renouncing saying something about the structural or systemic causes that generated it? Given the already mentioned analytical/descriptive origin of resilience, the problems that a move toward a normative approach produces, and the agents/system relationships it shapes, recourse to this concept means focusing on the outcomes as they emerge, rather than on the causes (agents and/or conditions) provoking the change. What does this mean and imply from a planning viewpoint? What does it mean to refer to the resilience of urban and territorial systems? Do we really need this concept for our purposes, why, and for whom?

Despite the criticism it received during its long dominance, the paradigm of sustainability kept together its three dimensions - the ecological, the social and the economic - harmonizing them within a normative and political viewpoint. While resilience (at least a part of resilience thinking) seemingly considers economy as under the laws of Nature subtracting it from the political domain. But in so doing, it resembles the laissez-faire economic theory, which bases its action on the - let us say - 'instinctive' ability of the "naked individual", and whose "foe to be dreaded is interference of government" - which represents the "artificial, that is political" opposed to the 'natural', that is economic, as John Dewey put it almost a century ago (Dewey, 1927, pp. 90-92). His interpretation fits perfectly with the assumed features of the discourse on resilience within the current neoliberal climate.

\section{Concluding remarks}

Swanstrom (2008, p. 6) argues that "applying the framework of ecological resilience to human institutions and governance processes generates paths to greater understanding, as well as dead ends". Given the potential inner contradictions and the ambiguity of the concept, moving toward resilience 'per se' could mean nothing, in the sense that the point would be how to reach or to provide a more resilient answer to critical situations, and why (and for whom, as Davoudi et al., 2012, p. 306). We can schematize the argument considering two debated ways of improving resilience: 1. Through spontaneous, self-adaptation capacity; 2 . Through collective, organized behavior and action. In the first case, the focus is on individual, autonomous, and spontaneous behavior and action; in the second case, on planned - organized actions. From the viewpoint of planning theory, it is rather clear that the emphasis on the first approach could be interpreted as a further step in weakening planning, implying that cities and regions are able to evolve even without its action, or even better without its action. Neoliberal policies are fed by rhetoric on individual capacities whose potential is limited and inhibited by rules and plans. This is clearly a simplification and a trivialization of the problem.

First of all, because self-adaptation ability and organized collective action are not necessarily antagonists.

In fact, it has been noticed that community resilience is not the sum of individual resilience (Hutter et al., 2011), and that individual, spontaneous actions do not substitute "great leadership and a culture of teamwork and trust which can respond effectively to the unexpected" (Seville, 2009, p. 11). On the other hand, the 
'self-organization' that leads to an increase of urban resilience is not that of individuals, but that of communities (Tidball \& Krasny, 2010).

Considering environmental risks and catastrophic events in particular, resilience is said to help increase the ability to adapt to whatever condition, and to immediately react to an emergency. To say this, we would need to understand how resilience has been actually translated and pursued in policies and actions, and with which implications. The findings from case studies of risk reduction policies and plans in Italy, which have been briefly mentioned, show that an emergency approach is prevailing. This emergency approach emphasizes the 'instant' ability to immediately take action in order to return as soon as possible to a previous condition, neglecting risk mitigation policies and plans that consider the post-emergency and rehabilitation as a chance to re-think urban or territorial systems in a wider and longer perspective. It tends to 'naturally' justify fast policies, reducing decision-making processes, while posing problems of participation and democracy (Pizzo \& Fabietti, 2013; Pizzo et al., 2013). The emphasis is put on short-term action and flexibility, instead of on prevention, which would aim at planning better and safer conditions in the long run.

Despite some interesting studies which try to harmonize resilience thinking and risk prevention (Tidball, 2010), recourse to the concept of resilience often helps divide these two mindsets, which are neither necessarily alternative nor opposite. Moreover, short-term and the long-term actions are both part of planning and some planning traditions keep both of these two mindsets as their own specific attitude. Searching and setting a 'desirable future', while also considering the possibility of reviewing it and the steps to achieve it remains crucial. Indeed, a great part of resilience contents and claims are already part of planning, both at a theoretical and practical level.

Resilience acquires different meanings if we apply it in the context of a specific, time-determined crisis generated by an 'unforeseeable' event, or 'unwanted' change. Flooding or earthquakes are quite different from banking crises or wars and generate quite different reactions. Recourse to the concept of resilience in all possible situations is not as 'obvious' as is often presented. In this sense, resilience cannot be assumed as an extended concept: not from a substantive point of view - its meaning must be specifically defined, its semantic field properly restricted; nor from a temporal point of view - the conditions it focuses on cannot be considered un-limited. Nevertheless, its normative translation is not straightforward to its properties as an analytical notion.

Resilience is said to represent a planning challenge if it leads to being considered not a "fixed asset, but as a continually changing process; not as a being but as a becoming" (Davoudi et al., 2012, p. 304). Some other interpretations claim that resilience challenges planning's linear assumptions and helps it to learn to coexist with "ontological uncertainties" (Wilkinson, Porter, \& Colding, 2010, p. 31 ). In this case we already noted that one of the primary tasks of planning since the crisis of the so called 'rational-comprehensive' paradigm is the management of uncertainty and continuous change. In this sense, resilience seems to be a new lens for looking at what is already known. However changing name is not a neutral operation, and the need to carefully consider the hidden meanings of this new word are clearly emerging.

Despite some recent efforts to assess the implications of recourse to the concept of resilience for planning theory, the field is still largely open for further inquiry. This represents a stimulating task. In fact, (a) to date, despite the questionable translation of resilience into a normative category, it has represented an object of normative planning rather than of critical planning theory since environmental-related questions tend to under-theorize power, politics and conflict and to depoliticize change (Swyngedouw, 2007, 2011); (b) planning theory gave minimal attention to environmental-ecological concerns (Wilkinson, 2011); but (c) there is a growing interest in substantive issues (Wilkinson, 2011).

Compared to its older related concepts, such as sustainability, and to younger mainstream ideas such as smart cities and green economy, it has a more contentious nature related to its analytical origin and to its controversial normative meaning, that could be disclosed through an in-depth analysis of its translation into practice. This means that, especially as regards planning, it does not suffice to say that it is a useful concept because of its neutrality and adaptability: For what purpose? Towards which objective? In which way? At the expenses of who or what?

Nevertheless, the concept of resilience is not 'readily' usable; it needs to be translated into operational tools and modalities of action whose outcomes remain uncertain.

More than a normative category resulting from the analytical domain, resilience could be taken as a 'by-product' or 'side effect' (Pizzo, 2005, 2007) of policies and actions addressed to manifold objectives as defined by planning. Since a by-product cannot be directly pursued, an abstract and vague call to resilience says nothing about the concrete changes that must be realized in order to obtain the desired results. A reason for the pervasiveness of resilience lies in this ambiguity, calling attention to its political nature and to its latent contentious implications. This represents a controversial and risky tool of neoliberal politics.

\section{References}

Ainuddin, S., \& Routray, J. K. (2012). Earthquake hazards and community resilience in Baluchistan. Natural Hazards, 63, 909-937.

Alexander, D. E. (2013). Resilience and disaster risk reduction: An etymological journey. Natural Hazards and Earth System Science, 13, 2707-2716. http://dx.doi. org/10.5194/nhess-13-2707-2013. <www.nat-hazards-earth-syst-sci.net/13/ 2707/2013>.

Anderies, J. M., Walker, B. H., \& Kinzig, A. P. (2006). Fifteen weddings and a funeral: Case studies and resilience-based management. Ecology and Society, 11(1), 21-32.

Berger, P. L., \& Luckmann, T. (1966). Social construction of reality: A treatise in the sociology of knowledge. Garden City, NY: Anchor Books.

Berkes, F., \& Folke, C. (1998). Linking social and ecological systems: Management practices and social mechanisms for building resilience. Cambridge: Cambridge University Press.

Brand, F. S., \& Jax, F. (2007). Focusing the meaning(s) of resilience: Resilience as a descriptive concept and a boundary object. Ecology and Society, 12(1), 23-38.

Carpenter, S. R., \& Brock, W. A. (2008). Adaptive capacity and traps. Ecology and Society, 13(2), 40. <http://www.ecologyandsociety.org/vol13/iss2/art40/>.

Chapin, F. S., III, Folke, C., \& Kofinas, G. P. (2009). A framework for understanding change. In F. S. Chapin, III, G. P. Kofinas, \& C. Folke (Eds.), Principles of ecosystem stewardship: Resilience-based natural resource management in a changing world (pp. 3-28). New York: Springer Science + Business Media.

Clark, W. C., \& Dickson, N. M. (2003). Sustainability science: The emerging research program. Proceedings of the National Academy of Sciences of the United States of America, 100(14), 8059-8061. http://dx.doi.org/10.1073/pnas.1231333100.

Cutter, S. L., Burton, C. G., \& Emrich, C. T. (2010). Disaster resilience indicators for benchmarking baseline conditions. JHSEM - Journal of Homeland Security and Emergency Management, 7(1). <http://www.bepress.com/jhsem/vol7/iss1/51>.

Davoudi, S., Brooks, E., \& Mehmood, A. (2013). Evolutionary resilience and strategies for climate adaptation, planning practice $\mathcal{E}$ research (Vol. 28, Issue 3, pp. 307322) (Special issue: Deconstructing planning and resilience: Lessons in translating theory to practice).

Davoudi, S., Shaw, K., Haider, L. J., Quinlan, A. E., Peterson, G. D., Wilkinson, C., Fünfgeld, H., McEvoy, D., Porter, L., \& Davoudi, S. (2012). Resilience: A bridging concept or a dead end? "Reframing" resilience: Challenges for planning theory and practice, interacting traps: Resilience assessment of a pasture management system in northern Afghanistan, urban resilience: What does it mean in planning practice? Resilience as a useful concept for climate change adaptation? The politics of resilience for planning: A cautionary note. Planning Theory E Practice, 13(2), 299-333.

Deleuze, G., \& Guattari, F. (1972). Anti-Oedipus. Paris: Les Editions de Minuit.

Dewey, J. (1927). The public and its problems. Athens: Ohio University Press: Swallow Press.

Folke, C. (2006). Resilience: The emergence of a perspective for social-ecological systems analyses. Global Environmental Change, 16, 253-267.

Folke, C., Carpenter, S. R., Walker, B., Scheffer, M., Chapin, T., \& Rockstrom, J. (2010). Resilience thinking: Integrating resilience, adaptability and transformability. Ecology and Society, 15(4), 20. <http://www.ecologyandsociety.org/vol15/iss4/ art20/>.

Friedmann, J. (2008). The uses of planning theory: A bibliographic essay. Journal of Planning Education and Research, 28(2), 247-257. 
Garschagen, M. (2011). Resilience and organisational institutionalism from a crosscultural perspective: An exploration based on urban climate change adaptation in Vietnam. Natural Hazards.

Gunderson, L. H., \& Holling, C. S. (2002). Panarchy: Understanding transformations in human and natural systems. Washington, DC: Island Press.

Harvey, D. (2005). A brief history of neoliberalism. Oxford, New York: Oxford University Press.

Holling, C. S. (1973). Resilience and stability of ecological systems. Annual Review of Ecological Systems, 4, 1-23.

Holling, C. S. (1996). Engineering resilience versus ecological resilience. In P. C. Schulze (Ed.), Engineering within ecological constraints (pp. 31-44). Washington, DC: National Academy Press.

Holling, C. S. (2001). Understanding the complexity of economic, ecological, and social systems. Ecosystems, 4, 390-405.

Hutter, G., Kuhlicke, C., Glade, T., \& Felgentreff, C. (2011). Natural hazards and resilience: Exploring institutional and organizational dimensions of social resilience. Natural Hazards, 60, 1-6.

Klein, R. J. T., Nicholls, R. J., \& Thomalla, F. (2003). Resilience to natural hazards: How useful is this concept? Environmental Hazards, 5, 35-45.

Mazza, L. (1995). Technical knowledge, practical reason and the planner's responsibility. Town Planning Review, 66(4), 389-410.

Mazza, L. (2002). Technical knowledge and planning actions. Planning Theory, 1(1), $11-26$.

Mazza, L. (2013). Which aims and knowledge for spatial planning? Some notes on the current state of the discipline, draft, unpublished.

Adger, W. N. (2000). Social and ecological resilience: Are they related? Progress in Human Geography, 24(3), 347-364.

Olsson, P., Gunderson, L. H., Carpenter, S. R., Ryan, P., Lebel, L., Folke, C., et al. (2006). Shooting the rapids: Navigating transitions to adaptive governance of socialecological systems. Ecology and Society, 11(1), 1-21.

Ott, K., \& Döring, R. (2004). Theorie und Praxis starker Nachhaltigkeit. Marburg, Germany: Metropolis Verlag.

Pendall, R., Foster, K. A., \& Cowell, M. (2010). Resilience and regions: Building understanding of the metaphor. Cambridge Journal of Regions, Economy and Society, 3(1), 71-84.

Pickett, S. T. A., Cadenasso, M. L., \& Grove, J. M. (2004). Resilient cities: Meaning, models, and metaphor for integrating the ecological, socio-economic, and planning realms. Landscape and Urban Planning, 69, 369-384.

Pickett, S. T. A., Parker, V. T., \& Fiedler, P. L. (1992). The new paradigm in ecology: Implications for conservation biology above the species level. In P. L. Fiedler (Ed.), Conservation biology: The theory and practice of nature conservation, preservation, and management (pp. 65-88). New York: Chapman and Hall.

Pizzo, B. (2005). Il paesaggio come costrutto strategico. Dottorato in Pianificazione Territoriale e Urbana, XVII ciclo. [PhD dissertation in Urban and Territorial Planning, Sapienza Università di Roma, Italy].

Pizzo, B. (2007). La costruzione del paesaggio. Roma: Officina Edizioni.

Pizzo, B., Di Salvo, G., Giuffré, M., \& Pellegrino, P. (2013). Earthquakes, the public space, and the social construction of environmental disasters. The role of the public space for risk mitigation and urban redevelopment/the role of environmental disasters for re-assessing the space of the Public. IJPP - Italian Journal of Planning Practices, 3(1). <http://ijpp.uniroma1.it/index.php/it>.

Pizzo, B., \& Fabietti, V. (2013). Environmental risk prevention, post-seismic interventions and the reconstruction of the public space as a planning challenge. An introduction. IJPP - Italian Journal of Planning Practices, 3(1). <http://ijpp.uniroma1.it/index.php/it>.

Prashar, S., Shaw, R., \& Takeuchi, Y. (2012). Assessing the resilience of Delhi to climate-related disasters: A comprehensive approach. Natural Hazards, 64 1609-1624.
Pulliam, H. R., \& Johnson, B. R. (2001). Ecology's new paradigm: What does it offer designers and planners? In B. R. Johnson \& K. Hill (Eds.), Ecology and design: Frameworks for learning (pp. 51-84). Washington, DC: Island Press.

Raco, M., \& Street, E. (2011). Resilience planning, economic change and the politics of post-recession development in London and Hong Kong. Urban Studies, 49(5), $1065-1087$.

Redman, C. L. (2014). Should sustainability and resilience be combined or remain distinct pursuits? Ecology and Society, 19(2), $37 . \quad<\mathrm{http}: / / \mathrm{www}$. ecologyandsociety.org/vol19/iss2/art37/19(2)>.

Resilience Alliance (2007a). Urban resilience research prospectus. A resilience alliance initiative for transitioning urban systems towards sustainable futures. CSIRO, Australia--Arizona State University, USA--Stockholm University, Sweden. <http://www.ehs.unu.edu/file/get/3648>.

Resilience Alliance (2007b). Assessing and managing resilience in social-ecological systems: A practitioners workbook (resilience alliance). <http://www.resalliance. org/3871.php>.

Sennet, R. (1998). The corrosion of character: The personal consequences of work in the New Capitalism. New York, London: W.W. Norton \& Company.

Seville, E. (2009). Resilience: Great concept... but what does it mean for organisations? In Ministry of Civil Defence and Emergency Management (Eds.), Community resilience: Research, planning and civil defence emergency management. Wellington, New Zealand: Ministry of Civil Defence \& Emergency Management.

Swanstrom, T. (2008). Regional resilience: A critical examination of the ecologica framework. IURD working paper series. Berkeley, CA: Institute of Urban and Regional Development, University of California.

Swart, R. J., Raskin, P., \& Robinson, J. (2004). The problem of the future: Sustainability science and scenario analysis. Global Environmental Change, 14(2), 137-146. http://dx.doi.org/10.1016/j.gloenvcha.2003.10.002.

Swyngedouw, E. (2011). Trouble with nature: Ecology as the new opium for the masses. In J. Hillier \& P. Healey (Eds.), The Ashgate research companion to planning theory: Conceptual challenges for spatial planning. Farnham, London: Ashgate.

Swyngedouw, E. (2007). Impossible ‘Sustainability’ and the post-political condition. In R. Krueger \& D. Gibbs (Eds.), The sustainable development paradox. New York: Guilford Press.

Taylor, P. (2005). Time: From hegemonic change to everyday life. In S. Holloway, S Rice, \& G. Valentine (Eds.), Key concepts in geography (pp. 146-152). London: Sage.

Tidball, K. G., Krasny, M. E. (2010). From risk to resilience: What role for community greening and civic ecology in cities? <http://www.public.asu.edu/ iacmao/ PGS191/Resilience\%20Readng\%20\%234.pdf>.

UNISDR (The United Nation's Office For Disaster Risk Reduction) (2012). Making cities resilient report.

Vale, L. J., \& Campanella, T. J. (2005). The resilient city: How modern cities recover from disaster. Oxford, UK - New York: Oxford University Press.

Walker, B., \& Salt, D. (2006). Resilience thinking: Sustaining ecosystems and people in a changing world. Washington, DC: Island Press,

Wenban-Smith, A. (2011). Planning and the recession: A UK perspective. Planning Theory and Practice, 12(3), 430-436.

Wildavsky, A. (1998). Searching for safety. Rutgers: Social Philosophy \& Policy Centre, The State University - New Jersey: Transaction Publisher.

Wilkinson, C. (2011). Social-ecological resilience: Insights and issues for planning theory. Planning Theory, 11(2), 148-169.

Wilkinson, C., Porter, L., Colding, J. (2010). Metropolitan planning and resilience thinking: A practitioner's perspective. Critical planning, summer (pp. 25-44).

Zolli, A., \& Healey, A. M. (2012). Resilience. Why things bounce back. New York: The Free Press. 